\title{
Estratégias alternativas na higienização de frutas e hortaliças
}

\section{Alternative strategies in sanitization of fruits and vegetables}

\author{
Jackline Freitas Brilhante de São José \\ Programa de Pós Graduação em Nutrição e Saúde, Universidade Federal do Espírito Santo, Departamento de Educação Integrada em Saúde, Campus Maruípe, CEP 29040-090, Vitória, ES, Brasil \\ ( ${ }^{\star} E-$-mail: jackline.jose@ufes.br) \\ http://dx.doi.org/10.19084/RCA16124
}

Recebido/received: 2016.09 .14

Recebido em versão revista/received in revised form: 2016.11.17

Aceite/accepted: 2016.12.06

\section{R E S U M O}

O consumo de frutas e hortaliças tem aumentado em função da sociedade moderna que procura hábitos de vida mais saudáveis. O consumidor atual utiliza cada vez mais alimentos mais próximos dos frescos, que apresentem conveniência e, ao mesmo tempo, qualidade microbiológica, sensorial e nutricional. A qualidade microbiológica de frutas e hortaliças está relacionada com a presença de microrganismos alteradores, que podem reduzir a vida útil desses produtos e a de microrganismos patogénicos que podem provocar doenças nos consumidores. A operação de lavagem juntamente com aplicação de desinfetantes é a etapa na qual pode ser reduzida a carga microbiana de forma a assegurar a segurança do produto. Os compostos clorados são amplamente utilizados na descontaminação, contudo, há interesse em utilizar outros, uma vez que estes geram resíduos tóxicos (trihalometanos) em presença de matéria orgânica em fase de decomposição. De entre as alternativas, a literatura indica a aplicação de outros desinfetantes químicos como peróxido de hidrogénio, ácido peroxicético, dióxido de cloro, ozono, ácidos orgânicos e descontaminantes físicos como os ultrassons.

Palavras chave: compostos clorados, qualidade dos alimentos, desinfetantes, ultrassons.

\section{A B S T R A C T}

The consumption of fruits and vegetables has increased with modern society seeking healthier lifestyles. Today consumers want fresh foods, with convenience and microbiological, sensory and nutritional quality. The microbiological quality of fruits and vegetables is related with the presence of spoilage microorganisms, which can reduce the shelf life of these products and the presence of pathogenic microorganisms that can cause illness in consumers. Washing step with sanitizers application is the stage which can be reduced microbial load to ensure safety product. Chlorinated compounds are widely used in descontamination, however, there is interest in using others since they generate toxic wastes, as trihalomethanes, in the presence of organic matter undergoing decomposition. Among the alternatives, the literature indicate the application of other chemical sanitizers such as hydrogen peroxide, peroxiacetic acid, chlorine dioxide, ozone, organic acids and physical descontaminating as ultrasound.

Keywords: chlorine compounds, food quality, sanitizers, ultrasound. 


\section{INTRODUÇÃO}

A nível mundial, o consumo anual de frutas e hortaliças apresentou um crescimento médio de 4,5\% entre os anos de 1990 e 2004 (Olaimat e Holley, 2012) estando esse aumento relacionado com a preocupação em se manter uma dieta alimentar saudável (Warriner et al., 2009; Forghani e Oh, 2013). O aumento da procura por alimentos mais saudáveis, aliado às exigências do consumidor (Ruíz-Cruz et al., 2007; Alegre et al., 2011), e à conveniência proporcionada pelos alimentos prontos (Glowacz et al., 2013) contribuíram para o aumento do consumo de frutas e hortaliças minimamente processadas (Graça et al., 2011; Joshi et al., 2013). Entende-se por produtos minimamente processados as frutas e hortaliças frescos que foram submetidos a um processo tecnológico que incluiu as operações de limpeza, lavagem, descascasque, corte, ou não, desinfeção, centrifugação e embalagem em atmosfera modificada, ficando prontos para consumo ou para preparação imediata, sem que percam a condição de produto fresco. Este processo proporciona, portanto, ao consumidor um produto semelhante ao fresco, com tempo de vida útil prolongado e, simultaneamente, com segurança microbiológica e manutenção da qualidade nutritiva e sensorial (Rico et al., 2007).

Porém, associado ao crescimento do mercado e ao consumo de produtos frescos e minimamente processados, os problemas específicos são de origem microbiológico, observando-se riscos pela presença de microrganismos de alteração que reduzem o tempo de vida útil (Kim e Song, 2017) bem como o aumento da incidência de toxinfeções alimentares por ingestão de frutas e hortaliças contaminadas por microrganismos patogénicos (Warriner et al., 2009; Kim e Song, 2017). Assim, o controle microbiológico desse tipo de produto ainda é um desafio para a indústria (Gunduz et al., 2010). A contaminação dos produtos pode surgir, no campo a partir do solo, da matéria orgânica, de fertilizantes orgânicos, da água de rega, insetos, animais ou contacto humano, nas práticas pós-colheita ou da ineficiência nas etapas de processamento (Heaton e Jones, 2008; Fernandes et al., 2014). De entre os microrganismos patogénicos de origem alimentar destacam-se Salmonella spp, estirpes enteropatogénicas de Escherichia coli, Listeria monocytogenes, Campylobacter jejuni e Shigella spp (Rico et al., 2007; Warriner et al., 2009). Em julho de 2011, um surto envolveu a presença de toxina Shiga produzida por Escherichia coli O104:H4 após o consumo de rebentos de feijão. Neste surto, foram registados 852 pacientes com síndrome urêmica hemolítica e 32 mortes (CDC, 2011). Outro exemplo é a contaminação por Salmonella neste tipo de alimentos, onde se estima que esta bactéria pode ser responsável por cerca de 3 milhões de casos de Doenças de Origem Alimentar (DOA) na China e de um milhão nos Estados Unidos da América (Guo et al., 2016). No Brasil, de 2000 a 2015, foram registrados 11.241 surtos por DOA, sendo a Salmonella a principal responsável pelo maior número de casos (14,3\%) (Brasil, 2015). Em todo mundo de 2013 a 2015, foram relatados vários surtos com Salmonella, sendo um deles, nos EUA, atribuído ao consumo de pepinos contaminados (CDC, 2013, 2015).

Deste modo, a operação de lavagem associada à aplicação de soluções desinfetantes é considerada a única etapa do processo na qual pode ser alcançada a redução no número de microrganismos, contribuindo assim, para a segurança de frutas e hortaliças (Cossu et al., 2017), dado serem considerados veículos de transmissão de patogénicos causadores de DOA. Portanto a não eficiência das etapas de limpeza, lavagem e desinfeção influenciarão diretamente a qualidade microbiológica do produto final (Olaimat e Holley, 2012).

A lavagem com água potável permite a remoção de componentes do solo e parte do número de patogénicos, mas não é suficiente para reduzir significativamente a carga microbiana (Joshi et al., 2013), portanto, a desinfeção constitui um ponto chave do processo (Gil et al., 2009; São José et al., 2014a).

De entre os desinfetantes utilizados na indústria alimentar, principalmente em produtos frescos, são os compostos à base de cloro e clorados (Alvaro et al., 2009). A facilidade de utilização, baixo custo, alta atividade antimicrobiana e completa dissolução em água, fazem com que sejam frequentemente utilizados (Selma et al., 2008).

A ação oxidante e desinfetante dos derivados clorados é controlada pelo ácido hipocloroso $(\mathrm{HClO})$, produto resultante da hidrólise da substância clorada, que é a forma de cloro livre disponível com amplo espectro de ação (Parish et al., 
2003; Andrade, 2008), contudo não garante a eliminação total dos microrganismos. A ação do ácido hipocloroso varia com o $\mathrm{pH}$ do meio, sendo que a concentração de $\mathrm{HClO}$ aumenta com decréscimo do valor de $\mathrm{pH}$. Quando em solução aquosa, este ácido dissocia-se para formar o ião hidrogênio e o ião hipoclorito. Assim, os compostos clorados são mais efetivos com valores de $\mathrm{pH}$ baixos, ou seja, quando a proporção de ácido hipocloroso é maior (Andrade, 2008).

Os compostos à base de cloro atuam nas células microbianas sob a forma de ácido hipocloroso ( $\mathrm{HClO})$, que libera oxigênio que se combina com os elementos do protoplasma celular. O cloro pode, ainda, associar-se às proteínas da membrana celular e alterar o metabolismo microbiano (Andrade, 2008). As concentrações recomendadas de cloro residual livre para a desinfeção de frutas e hortaliças variam de 50 a $200 \mathrm{mg} . \mathrm{L}^{-1}$ com um tempo de contato de 1 a 30 minutos (Ruiz-Cruz et al., 2007). No processamento mínimo, em condições típicas de lavagem de frutas e hortaliças, a eficiência do cloro é limitada, alcançando a redução de um a dois ciclos logarítmicos na população microbiana (Park et al., 2009).

Ressalta-se ainda a possibilidade da hipercloração da água residual, pois associada ao alto conteúdo de carbono orgânico pode contribuir para o aumento da concentração de trihalometanos e de outros subprodutos da desinfeção (Selma et al., 2008). Os trihalometanos são considerados carcinogénicos e indicadores da possível presença de outros compostos organoclorados. O limite de risco médio para desenvolvimento de cancro é de 60 e 40 miligramas por litro para o clorofórmio e bromofórmio, respectivamente (Andrade, 2008). Deste modo, como os compostos clorados têm sido foco de preocupação ambiental têm surgido diversas técnicas de desinfecção alternativas. (Ongeng et al., 2006; Rico et al., 2007; Ruiz-Cruz et al., 2007). A aplicação de cloro a produtos minimamente processados é proibida em alguns países da Europa como Holanda, Suécia, Alemanha e Bélgica (Rico et al., 2007).

A utilização de peróxido de hidrogênio, ácido peroxiacético, dióxido de cloro, ozonização, ácidos orgânicos e a utilização de ultrassons associado ou não aos compostos químicos tem sido proposta como estratégias alternativas para a higienização de frutas e hortaliças. Deste modo este artigo tem como objetivo discutir os princípios de inativação de cada método bem como a aplicação na etapa de lavagem e desinfeção de frutas e hortaliças.

\section{Peróxido de Hidrogênio}

O peróxido de hidrogênio é considerado um produto fortemente oxidante capacidade de reduzir radicais livres que reagem com componentes celulares essenciais, incluindo proteínas, lipídeos e DNA (Kitis, 2004). De acordo com a concentração, este desinfetante pode ter efeito bacteriostático ou bactericida. Apesar de ser considerado eficiente, muitos fungos e bactérias podem ser resistentes, nomeadamente, pela formação de glutationa associado a enzimas e pela produção de catalase (Caixeta, 2008). Este desinfetante é estudado como alternativa ao cloro e, em geral, reconhecido como seguro (GRAS) para algumas aplicações na indústria de leite, ovos, chá e vinhos em processos de clarificação e também como antimicrobiano (Olmez e Kretzschmar, 2008).

Apresenta a vantagem de gerar resíduos que rapidamente são transformados pela enzima catalase em água e oxigênio, baixa toxicidade e não necessitando os produtos tratados de enxaguamento após a aplicação. Porém, apresenta como inconvenientes o poder corrosivo sobre cobre, bronze e zinco, necessitar de longo tempo de contacto quando usado em baixas temperaturas e exigir precauções durante a manipulação e dosagem (Artés et al., 2009).

Ukuku (2004) ao utilizar peróxido de hidrogênio a $1 \%$ no tratamento de melão, minimamente processado contaminado com Salmonella spp., observou uma redução significativa na contagem deste microrganismo, não tendo sido detetados sobreviventes após a etapa de higienização, e ausência do patogénico ao longo do período de armazenamento a $5{ }^{\circ} \mathrm{C}$. Ukuku (2004) observou que a aplicação de peróxido de hidrogênio a 2,5\% durante 5 minutos causou redução significativa na contagem de bactérias mesófilas aeróbias, fungos filamentosos e leveduras na superfície de melões, assim como verificou ainda que o tratamento reduziu a $L$. monocytogenes em aproximadamente $3 \mathrm{log}$ UFC.g-1. 
Huang e Chen (2012) observaram reduções de 1,1 e 1,5 log UFC.g-1 de Escherichia coli O157:H7 em espinafres tratados, respectivamente, com soluções de 1 e $2 \%$ de peróxido de hidrogênio a $22^{\circ} \mathrm{C}$. Guo et al. (2016) ao avaliar a ação de peróxido de hidrogênio a 2,5 e $5 \%$ durante um minuto em fatias de pepino intencionalmente contaminadas com Salmonella Choleraesuis observaram uma redução de 0,9 e 1,6 $\log$ UFC.g-1, respectivamente.

\section{Ácido peroxiacético}

O ácido peroxicético também pode ser utilizado como alternativa aos compostos clorados na higienização de frutas e hortaliças. É produzido pela reação entre ácido acético ou anidrido acético com peróxido de hidrogênio na presença de ácido sulfúrico, que tem função de catalisador da reação (Andrade, 2008). Trata-se de um agente oxidante forte e desinfetante, com potencial oxidativo maior que o do cloro e do dióxido de cloro. A sua atividade não é influenciada pela temperatura, $\mathrm{pH}$ e presença de matéria orgânica. (Artés et al., 2009). A ação antimicrobiana é devida à liberação de oxigénio ativo, responsável pela oxidação de ligações sulfidrilas de proteínas, enzimas e outros metabólitos (Kitis, 2004; Srey et al., 2013). Além disso, é sugerido ainda a ação deste ácido no rompimento da função quimiostática de proteínas e lípidos da membrana citoplasmática e do transporte, em função do deslocamento da parede celular. Em células gram-negativas, esse desinfetante também é efetivo por atuar em lipoproteínas da membrana celular e, no interior das células, poder promover desestruturação metabólica, pela oxidação de enzimas essenciais, o que corrompe vias metabólicas vitais, transporte ativo de membrana e alterar ações na concentração de solutos intracelulares (Andrade, 2008). Contudo apresenta como vantagem, em relação aos compostos clorados, não produzir subprodutos tóxicos ou mutagénicos. Entretanto, é um produto que tem odor pungente e requer cuidados durante a manipulação (Kitis, 2004; Srey et al., 2013).

A FDA (Food and Drug Administration) estipulou que soluções contendo no mínimo $85 \mathrm{mg} . \mathrm{L}^{-1}$ de ácido peroxicético devem ser usadas na higienização e superfícies onde os alimentos são manipulados, onde a concentração pode variar até 300
mg.L-1 (Álvaro et al., 2009). Este mesmo órgão regulamentador aprovou a utilização de ácido peroxicético para a desinfecção de produtos vegetais em concentrações que não ultrapassem $80 \mathrm{mg} \cdot \mathrm{L}^{-1}$ (Ruíz-Cruz et al., 2007).

A utilização de ácido peroxiacético a $80 \mathrm{mg} \cdot \mathrm{L}^{-1}$ durante de 5 minutos na desinfeção de coentros minimamente processado, demonstrou ter a possibilidade de substituir o dicloroisocianurato de sódio, devido a redução de cerca de 2 log UFC.g-1 da população de Escherichia coli (Srebernich, 2007). Ruíz-Cruz et al. (2007) avaliaram o efeito do ácido peroxiacético, na desinfeção de cenoura minimamente processada, e observaram uma redução significativa na população de Salmonella de cerca de 2,1 log UFC.g- ${ }^{-1}$.

O poder oxidante do ácido peroxiacético sobre as células microbianas tem sido demonstrado em vários trabalhos. Poucos trabalhos têm discutido os efeitos deste desinfetante nas características sensoriais e nutricionais das frutas e hortaliças, pelo que se sugere que sejam avaliados esses efeitos por forma a que seja avaliada a sua eficiência em todos aspectos que envolvem qualidade de alimentos.

\section{Dióxido de cloro}

Outro potente agente oxidante reconhecido como desinfetante, desde 1900, é o dióxido de cloro (Mahmound e Linton, 2008; Kim e Song, 2017). Este composto pode ser produzido por meio de duas reações: reação de um ácido com cloreto de sódio ou a reação do cloreto de sódio com gás cloro. Há indícios de que sua capacidade oxidante seja 2,5 vezes maior que a do cloro e menos reativo com matéria orgânica (López-Gálvez et al., 2009; Kim e Song, 2017). Assim, apesar de ser um composto clorado, não produz quantidades significativas de trihalometanos, não sendo de risco ambiental nem para a saúde. A atividade antimicrobiana do dióxido de cloro é independente do valor de $\mathrm{pH}$ da solução desinfetante. A ação do dióxido de cloro é fundamentada na reação de oxidação de proteínas da membrana celular, incluindo aquelas envolvidas no transporte de solutos. Pela facilidade de penetração na membrana celular de bactérias, provoca alterações transmembranas dos gradientes iónicos e inibe a respiração celular. 
Atua ainda na oxidação de grupos sulfidrilas (-SH) em enzimas com formação de dissulfito (-S-S-), que são análogos sem função (Ölmez e Kretzschnar, 2009; Kim e Song, 2017).

Apesar da estabilidade do dióxido de cloro ser superior à do cloro, este apresenta instabilidade durante a produção e armazenagem, portando torna-se necessário à sua preparação imediatamente antes da utilização (López-Gálvez et al., 2009). A forma aquosa do dióxido de cloro é amplamente utilizada pela indústria de alimentos e pode ser usada como desinfetante para superfícies que entram em contato com alimentos (López-Gálvez et al., 2009).

Na literatura há diversos registros de avaliação deste desinfetante em produtos minimamente processados. Morangos desinfetados com $5 \mathrm{mg} \cdot \mathrm{L}^{-1}$ de gás dióxido de cloro por 10 minutos, apresentaram uma redução de quatro ciclos logarítmicos comparada com a contagem inicial de mesófilos e, durante o armazenamento, a população manteve-se em números não detectáveis até o 12.. dia (Mahmound et al., 2007). Srebernich (2007) usou solução de dióxido de cloro a $50 \mathrm{mg} . \mathrm{L}^{-1}$, durante 10 minutos em coentros e observou uma redução de três ciclos logarítmicos na população de coliformes totais, tendo concluido que este desinfetante pode ser uma alternativa ao hipoclorito de sódio.

Apesar da eficiência microbiológica apresentada em diversos trabalhos nos quais foi aplicado o dióxido de cloro, vale ressaltar que quando comparado com os demais compostos clorados, a sua aplicação requer um considerável investimento inicial na aquisição do equipamento. O responsável pela seleção do desinfetante a ser aplicado nos alimentos, deve ter conhecimento dos vários aspectos relacionados com este procedimento assim como com a eficiência na redução da contaminação, custo da aplicação e possíveis efeitos deletérios nas características sensoriais e nutricionais.

\section{Ozono}

O ozono é uma forma triatómica do oxigênio que tem sido avaliado quanto à aplicação no processamento de alimentos devido ao seu alto poder desinfetante e rápida degradação, o que impede a formação de resíduos nos alimentos tratados (Horváth et al., 1985). Elimina os microrganismos pela oxidação progressiva de componentes celulares vitais de forma a impedir o crescimento microbiano, e consequentemente permite aumentar a vida de prateleira de diversas frutas e hortaliças (Horváth et al., 1985; Parish et al., 2003; Silva et al., 2015).

O FDA, por considerá-lo substância GRAS, autorizou a sua aplicação no processo de lavagem de garrafas para comercialização de água nos Estados Unidos em 1982 (Chiattone et al., 2009). No entanto, foi utilizado pela primeira vez como agente conservante de alimentos em 1909, na forma gasosa, em câmaras frias de armazenagem de carnes (Chiattone et al., 2009).

Os principais sistemas de aplicação incluem a fase gasosa (exposição cíclica ou contínua ou por imersão em soluções ozonizadas (Aguayo et al., 2006). Em comparação com o cloro, o ozono é um potente desinfetante, que se decompõe rapidamente sem deixar resíduos (Silva et al., 2015). Contudo, é importante ressaltar que a sua aplicação requer cuidados por se tratar de um gás extremamente tóxico e pela possibilidade de formação de compostos bromados em água quando em presença do ião brometo. As concentrações deste gás devem ser controladas durante a aplicação uma vez que podem tornar-se tóxicas (Silva et al., 2011).

Cavalcante et al. (2014) observaram que a água ozonizada utilizada nas concentrações de 0,6, 0,8 e 1,0 mg. $\mathrm{L}^{-1}$ nos tempos de contacto de 1, 3 e 5 minutos provocou diferentes níveis de inativação de E. coli O157:H7 e de esporos de B. subtilis.

Zambre et al. (2010) verificaram que o ozono desempenhou um papel importante no aumento da vida de prateleira de tomates, uma vez que além de retardar o processo de maturação reduziu a alteração superficial causada por microrganismos, retardou ainda o desenvolvimento de cor vermelha, aumentou o tempo de vida útil para 12 dias quando armazenadas a $15^{\circ} \mathrm{C}$. Kim et al. (1999) observarem uma redução na contagem de E. coli O157: H7, P. fluorescens, L. mesenteroides e L. monocytogenes para valores entre 1,5 e $5 \log$ UFC $\mathrm{g}^{-1}$ ao aplicar $1,5 \mathrm{mg} \cdot \mathrm{L}^{-1}$ de água ozonizada $\left(25^{\circ} \mathrm{C}\right)$ 
durante 15 segundos. Selma et al. (2008) investigaram a eficiência do ozono gasoso na eliminação de Salmonella quando inoculada em casca de melão e observaram que uma concentração de 10000 mg.L $\mathrm{L}^{-1}$ durante 30 minutos a vácuo reduziu a contagem de Salmonella em melões não-maduros e melões maduros a 4,2 e $2,8 \log$ UFC, respectivamente. Além disso, foi observado que o melão minimamente processado tratado com ozono gasoso, foi mantido a nível aceitável de qualidade visual, aroma e firmeza durante o armazenamento de 7 dias a $5^{\circ} \mathrm{C}$.

Morais et al. (2015) observaram que o uso de ozono gasoso foi eficiente para a pós-colheita de morangos, sendo que os níveis de microrganismos permaneceram dentro dos limites aceitáveis e as propriedades físicas e químicas foram preservadas.

\section{Ácidos orgânicos}

Os ácidos orgânicos são constituintes naturais de muitos alimentos e também são amplamente utilizados como aditivos (compostos GRAS) para conservação de alimentos devido a atividade antimicrobiana. A ação conservante é em parte devido à ação sobre o $\mathrm{pH}$ do alimento, principalmente os devido a moléculas não dissociadas de ácido. Nesta forma, os ácidos podem difundir-se através da membrana da célula microbiana e, quando o $\mathrm{pH}$ intracelular é maior do que a do meio circundante, dissociam-se, liberando protões que provocam acidificação do citoplasma. Para eliminar os protões em excesso e manter o $\mathrm{pH}$ interno, as células têm que gastar energia e assim, alteram as atividades metabólicas. Dessa forma, há alteração do transporte de nutrientes devido à alteração da permeabilidade da membrana, quelação de iões metálicos e redução da força protónica motora (Huang e Chen, 2011).

Os ácidos lático, cítrico, acético e tartárico têm sido descritos como fortes antimicrobianos atuando sobre microrganismos mesófilos e psicrotróficos em frutas e hortaliças. De entre os ácidos orgânicos mais utilizados estão os ácidos acético, lático e ascórbico. O ácido acético é aplicado como um agente antimicrobiano seguro, e quando utilizado em baixas concentrações, normalmente não causa efeitos secundários.
O ácido ascórbico e seus derivados são GRAS quando utilizados como antioxidantes em frutas, hortaliças e sumos de frutas para prevenir o escurecimento e reações oxidativas (Rico et al., 2007). Os ácidos lático, acético e cítrico têm capacidade de inibir o crescimento de E. coli O157:H7, Listeria monocytogenes e Salmonella spp. em produtos frescos (Akbas e Ölmez, 2007). Em estudo de Huang e Chen (2011), o uso de ácido lático a 1\% foi o mais eficiente promovendo uma redução de $1,9 \log \mathrm{UFC}_{\text {. }} \mathrm{g}^{-1}$ de E. coli O157:H7 em espinafres. Concentrações de 0,5\% de ácido lático ou de ácido cítrico aplicadas por 2 minutos mostraram-se tão eficientes como uma solução clorada a $100 \mathrm{mg} \cdot \mathrm{L}^{-1}$ para redução da população de E. coli e L. monocytogenes inoculadas em alfaces minimamente processadas (Akbas e Ölmez, 2007). Os mesmos autores verificaram maior eficiência do ácido lático $\left(5 \mathrm{~mL} \mathrm{~L}^{-1}\right)$ e do ácido cítrico (5 g.. $\left.\mathrm{L}^{-1}\right)$, em relação à água ozonizada $\left(4 \mathrm{mg} . \mathrm{L}^{-1}\right)$ e à solução clorada (100 mg.L $\left.\mathrm{L}^{-1}\right)$ na desinfeção de alfaces minimamente processadas (Akbas e Ölmez, 2007). Sagong et al. (2011) também constataram o efeito sinérgico na utilização de ácido lático, cítrico e málico (todos a $2 \%$ ) combinados com ultrassons $(40 \mathrm{kHz})$, por 5 minutos, na inativação de E. coli O157:H7, Salmonella Typhimurium e L. monocytogenes inoculadas em alfaces orgânica, sem afetar significativamente a cor e textura. São José et al. (2014b) ao aplicarem ácido lático a $1 \%$ observaram uma redução de 1,80 log UFC.g ${ }^{-1}$ e 2,00 $\log$ UFC. $g^{-1}$ nas hortaliças, respectivamente. Dados semelhantes aos achados de Park et al. (2009), em que o ácido lático $1 \%$ reduziu $1,78 \log \mathrm{UFC}_{\mathrm{g}}{ }^{-1} \mathrm{e}$ o ácido lático $2 \%$ reduziu 2,53 log UFC.g-1 em amostras de maçãs contaminadas com Salmonella Typhimurium.

\section{Ultrassons}

O ultrassom é uma tecnologia adotada na indústria como descontaminante de superfícies e a sua utilização tem sido recomendada na indústria alimentar (Sango et al., 2014; São José et al., 2014a). No processamento de alimentos, os ultrassons de alta intensidade em baixas frequências de 20 a $100 \mathrm{kHz}$ têm tido efeito na inativação de microrganismos. Esta inativação é consequência da cavitação, que consiste na formação, crescimento e colapso de bolhas, que geram uma energia mecânica e química localizada. A cavitação gera 
condições localizadas de altas temperaturas e pressões denominadas de hot spots, além de liberar radicais livres que são gerados em função da dissociação de vapores presos nas bolhas. Também é gerada turbulência localizada e microcirculação de líquidos. Estas alterações promovidas pela cavitação contribuem para a ação de limpeza sobre as superfícies (Piyasena et al., 2003; Gogate e Kabadi, 2009; São José et al., 2014a).

Quando os ultrassons são aplicados associado com agentes químicos como $\mathrm{Cl}_{2}, \mathrm{H}_{2} \mathrm{O}_{2}, \mathrm{O}_{3} \mathrm{o}$ intenso gradiente de pressão permite a penetração desses agentes oxidantes pela membrana celular dos microrganismos. Além disso, a cavitação pode facilitar a desagregação de microrganismos presentes e assim, aumentar a eficiência dos desinfetantes químicos (Gil et al., 2009).

Esta tecnologia proporciona vantagens em termos de rendimento, com melhor tempo de processamento, melhoria da qualidade, redução dos danos químicos e riscos físicos. A aplicação de ultrassons tem atraído a atenção pelo papel na sustentabilidade do meio ambiente e por não causar danos, enquadrando-se no conceito de tecnologia verde (São José et al., 2014a; Rosário et al., 2017). Outro fator importante para a sua utilização na indústria alimentar é o facto de não gerar odores desagradáveis e não ocasionar perda significativa de nutrientes, somado ao facto da possibilidade de ser aplicado à temperatura ambiente e sem libertação de calor (Piyasena et al., 2003). Estas características permitem que esse processo seja aplicável a higienização de frutas e hortaliças.

Apesar de grande parte dos estudos com ultrassons ser realizada em sistemas líquidos (Piyasena et al., 2003), sabe-se que microrganismos contaminantes em alimentos sólidos também podem ser inativados por estas ondas (São José e Vanetti, 2012, 2015; Birmpa et al., 2013). A associação de ultrassons a agentes químicos pode contribuir para a inativação de microrganismos (São José e Vanetti, 2015; Rosário et al., 2017).

Birmpa et al. (2013) ao tratar alfaces com ultrassons $37 \mathrm{kHz}$ durante $30 \mathrm{~min}$ observaram reduções de $1,71,1,88,2,30$ e 5,72 logs UFC. ${ }^{-1}$ na contagem de S. aureus, L. innocua, E. coli e S. Enteritidis, respectivamente. Seymour et al. (2002) registaram que a associação de ultrassons com hipoclorito de sódio a $50 \mathrm{mg} \cdot \mathrm{L}^{-1}$ reduziu $1,2 \mathrm{log}$ UFC.g-1 de células de Salmonella Typhimurium em alface em comparação com o efeito produzido por tratamento apenas com solução clorada. Huang et al. (2006) aplicaram ultrassons $170 \mathrm{kHz}$ combinado ao dióxido de cloro $20 \mathrm{mg} \cdot \mathrm{L}^{-1}$ e observaram uma redução de cerca de $4 \log$ UFC. $\mathrm{g}^{-1}$ na população de Salmonella e E. coli O157:H7. Zhou et al. (2009) também observaram uma redução de 0,7 a 1,1 ciclo log na contagem de E. coli O157:H7 em espinafres quando tratados com ultrassons combinado com desinfetantes relativamente ao resultado obtido apenas com o desinfetante. São José e Vanetti (2012) avaliaram o efeito de ultrassons associado ao ácido peroxicético na remoção de $S$. Typhimurium à superfície de tomate cereja e observaram uma redução de $4 \log$ UFC. $g^{-1}$. Cao et al. (2010) relataram que os ultrassons são eficientes para inibir a incidência de alteração e preserva a qualidade no pós-colheita de morangos. Resultado semelhante foi obtido por Chen et al. (2011) que verificaram que a utilização de dióxido de cloro combinado com ultrassons permite a manutenção da qualidade no pós-colheita de ameixa japonesa (Prunus salicina L.). Forghani e Oh (2013) ao avaliar o efeito dos ultrassons $40 \mathrm{kHz}$ associado á água eletrolizada seguido do enxaguamento em água em alfaces previamente contaminados com E. coli O157:H7, observou uma redução 2,6 log UFC.g ${ }^{-1}$ da contagem desta bactéria. São José e Vanetti (2015) ao combinarem ultrassons (10 minutos, $45 \mathrm{kHz}$ ) com ácido peroxicético a 40 mg.L-1 obtiveram uma redução de 4 log UFC.g-1 na população de fungos filamentosos e leveduras em morangos, enquanto que o ácido peroxicético isoladamente reduziu em 2,9 log de UFC.g-1 ${ }^{-1}$. Estes resultados indicam que os ultrassons associado a outros desinfetantes têm capacidade para potenciar a redução da carga microbiana.

Estes estudos têm demonstrado a eficiência dos ultrassons na inativação microbiana quando aplicado na etapa de higienização. É evidente que a combinação do processo de cavitação associado a agentes químicos, como ácidos orgânicos, pode potenciar a redução da contagem de microrganismos. Entretanto, são necessários mais estudos relacionados com os efeitos gerados sobre as características sensoriais e nutricionais, uma vez que se trata de um método físico de higienização. 


\section{CONCLUSÃO}

Embora existam diferentes desinfetantes utilizados no controle microbiológico de frutas e hortaliças minimamente processadas, a sobrevivência de microrganismos de alteração e patogénicos irá influenciar diretamente a conservação, a qualidade e a segurança do produto final. Para fornecer respostas adequadas às necessidades da indústria de processamento mínimo, os métodos de higienização que visam a substituição do cloro devem ser bem avaliados para permitir a aplicação e garantir que o produto final não oferece riscos a nível microbiológico e mantêm as características sensoriais e nutricionais do alimento.

\section{REFERÊNCIAS BIBLIOGRÁFICAS}

Aguayo, E., Escalona, V. \& Artés, F. (2006) - Effect of the cyclic exposure to ozone gas on phytochemical, sensorial and microbial quality in whole and sliced tomatoes. Postharvest Biology and Technology, vol. 39, p. 166-177. http://dx.doi.org/10.1016/j.postharvbio.2005.11.005

Akbas, M. \& Ölmez, H. (2007) - Inactivation of Escherichia coli and Listeria monocytogenes on iceberg lettuce by dip wash treatments with organic acids. Letters in Applied Microbiology, vol. 44, n. 6, p. 619-624. http:/l dx.doi.org/10.1111/j.1472-765X.2007.02127.x

Alegre, I.; Viñas, I.; Usall, J.; Anguera, M. \& Abadias, M. (2011) - Microbiological and physicochemical quality of fresh-cut Apple enriched with the probiotic strain Lactobaccillus rhamnosus GC. Food Microbiology, vol. 28, n. 1, p. 59-66. http://dx.doi.org/10.1016/j.fm.2010.08.006

Álvaro, J. E.; Moreno, S.; Dianez, F.; Santos, M.; Carrasco, G. \& Urrestarazu, M. (2009) -Effects of peracetic acid disinfectant on the postharvest of some fresh vegetables. Journal of Food Engineering, vol. 95, n. 1, p. 11-15. http://dx.doi.org/10.1016/j.jfoodeng.2009.05.003

Andrade, N. J. (2008) - Higiene na Indústria de Alimentos. Varela, São Paulo. 412 p.

Artés, F.; Gómez, P.; Aguayo, E., Escalona, V. \& Artés-Hernandez, F. (2009) - Sustainable sanitation techniques for keeping quality and safety of fresh-cut plant commodities. Postharvest Biology and Technology, vol. 51, n. 3, p. 287-296. http://dx.doi.org/10.1016/j.postharvbio.2008.10.003

Birmpa, A.; Sfika, V. \& Vantakaris, A. (2013) - Ultraviolet light and Ultrasound as non thermal treatments for inactivation of micro-organisms in fresh read-to-eat foods. International Journal of Food Microbiology, vol. 167, n. 1, p. 96-102. http://dx.doi.org/10.1016/j.ijfoodmicro.2013.06.005

Brasil (2013) - Métodos Analíticos Oficiais para Análises Microbiológicas para Controle de Produtos de Origem Animal e Água. Instrução Normativa n. 62, de 26/08/2003. Diário Oficial da União, Ministério da Agricultura, Pecuária e Abastecimento, Secretaria de Defesa Agropecuária. Brasília, 18 set. 2003. Seção I, p. 14-51. [cit. 2013.08.31]. http://extranet.agricultura.gov.br/sislegisconsulta/consultarLegislacao.do?operAcao=visualizar\&id=2851

Brasil (2015) - Surtos por Salmonella: dados estatísticos, sintomas e prevenção. [cit. 2016.06.22]. http://u.saude.gov.br/ images/pdf/2015/novembro/09/Apresenta----o-dados-gerais-DTA-2015.pdf

Caixeta, D.S. (2008) - Sanificantes químicos no controle de biofilmes formados por duas espécies de Pseudomonas em superfície de aço inoxidável. 75 f. Dissertação (Mestrado em Microbiologia Agrícola) - Universidade Federal de Lavras, Lavras.

Cao, S.; Hu, Z.; Pang, B.; Wang, H.; Xie, H. \& Wu, F. (2010) - Effect of ultrasound treatment on fruit decay and quality maintenance in strawberry after harvest. Food Control, vol. 21, n. 4, p. 529-532. http://dx.doi. org/10.1016/j.foodcont.2009.08.002

Cavalcante, D.A.; Júnior, B.R.C.L.; Tribst, A.A.L. \& Cristianini, M. (2014) - Inativação de Escherichia coli O157:H7 e Bacillus subtilis por água ozonizada. Boletim do Centro de Pesquisa de Processamento de Alimentos, vol. 32, n. 1, p.105-112. http://dx.doi.org/10.5380/cep.v32i1.36931

CDC (2011) - Centers for Disease Control and Prevention Investigation update: Shiga toxin-producing E. coli O104 (STEC O104:H4) infections associated with travel to Germany. Centers for Disease Control and Prevention. [cit. 2016.09.06]. http://www. cdc.gov/ecoli/2011/ecoliO104/ 
CDC (2013) - Multistate outbreak of Salmonella Saintpaul infections linked to imported cucumbers (Final Update). Centers for Disease Control and Prevention. [cit. 2016.06.07]. http://www.cdc.gov/Salmonella/saintpaul-04-13/ index.html

CDC (2015) - Multistate outbreak of Salmonella Poona infections linked to imported cucumbers. Centers for Disease Control and Prevention. [cit. 2016.07.03]. http://www.cdc.gov/salmonella/poona-09-15/index.html

Chen, Z. \& Zhu, C. (2011) - Combined effects of aqueous chlorine dioxide and ultrasonic treatments on postharvest storage quality of plum fruit (Prunus salicina L.). Postharvest Biology and Technology, vol. 61, n. 2, p. 117-123. http://dx.doi.org/10.1016/j.postharvbio.2011.03.006

Chiattone, P.V.; Torres, L.M. \& Zambiazi, R.C. (2008) - Aplicação do ozônio na indústria de alimentos. Alimentos e Nutrição, vol. 19, n. 3, p. 341-349.

Cossu, A.; Le, P.; Young, G.M. \& Nitin, N. (2017) - Assessment of sanitation of efficacy against Escherichia coli 0157:H7 by rapid measurement of intracelular oxidative stress, membrane damage or glucose active uptake. Food Control, vol. 71, p. 293-300. http://dx.doi.org/10.1016/j.foodcont.2016.07.009

Fernandes, P.É.; São José, J.F.B.; Zerdas, E.R.M.A.; Andrade, N.J.; Fernandes, C.M. \& Silva, L.D. (2014) Influence of the hydrophobicity and surface roughness of mangoes and tomatoes on the adhesion of Salmonella enterica serovar Typhimurium and evaluation of cleaning procedures using surfactin. Food Control, vol. 41, p. 21-26. http://dx.doi.org/10.1016/j.foodcont.2013.12.024

Forghani, F. \& Oh, D. (2013) - Hurdle enhancement of slightly acidic electrolyzed water antimicrobial efficacy on Chinese cabbage, lettuce, sesame leaf and spinach using ultrasonication and water wash. Food Microbiology, vol. 36, n. 1, p. 40-45. http://dx.doi.org/10.1016/j.fm.2013.04.002

Gil, M.I.; Selma, M.V.; López-Gálvez, F. \& Allende, A. (2009) - Fresh-cut product sanitation and wash water disinfection: problems and solutions. International Journal of Food Microbiology, vol. 134, n. 1-2, p. 37-45. http://dx.doi.org/10.1016/.ijfoodmicro.2009.05.021

Glowacz, M.; Mogren, L.M.; Reade, J.P.H.; Cobb, A.H. \& Monaghan, J.M. (2013) - Can hot water treatments enhance or maintain postharvest quality of spinach leaves? Postharvest Biology and Technology, vol. 81, p. 23-28. http://dx.doi.org/10.1016/j.postharvbio.2013.02.004

Gogate, P.R. \& Kabadi, A.M. (2009) - A review of applications of cavitation in biochemical engineering/ biotechnology. Biochemical Engineering Journal, vol. 44, n. 1, p. 60-72. http://dx.doi.org/10.1016/j.bej.2008.10.006

Graça, A.; Abadias, M.; Salazar, M. \& Nunes, C. (2011) - The use of electrolyzed water as a disinfectant for minimally processed apples. Postharvest Biology and Technology, vol. 61, n. 2-3, p. 172-177. http://dx.doi. org/10.1016/j.postharvbio.2011.04.001

Gündüz, G.T.; Gönül, S.A. \& Karapinar, M. (2010) - Efficacy of sumac and oregan in inactivation of Salmonella Typhimurium on tomatoes. International Journal of Food Microbiology, vol. 141, n. 1-4, p. 39-44. http://dx.doi. org/10.1016/j.ijfoodmicro.2010.04.021

Guo, Y.; Li, M.; Han, H. \& Cai, J. (2016) - Salmonella enterica serovar Choleraesuis on fresh-cut cucumber slices after reduction treatments. Food Control, vol. 70, p. 20-25. http://dx.doi.org/10.1016/j.foodcont.2016.05.030

Heaton, J.C. \& Jones, K. (2008) - Microbial contamination of fruit and vegetables and the behaviour of enteropathogens in the phyllosphere: a review. Journal of Applied Microbiology, vol. 104, n. 3, p. 613-626. http://dx.doi.org/10.1111/j.1365-2672.2007.03587.x

Horváth, M.; Bilitzky, L. \& Hüttner, J. (1985) - Bactericidal, sterilizing and other effects in lower organisms. In: Ozone. Science, Budapest. cap. 3, p. 69-74.

Huang, T.S.; Xu, C.L.; Walker, K.; West, P.; Zhang, S.Q. \& Weese, J. (2006) - Decontamination efficacy of combined chlorine dioxide with ultrasonication on apples and lettuce. Journal of Food Science, vol.71, n. 4, p. M134-M139. http://dx.doi.org/10.1111/j.1750-3841.2006.00015.x

Huang, Y. \& Chen, H. (2011) - Effect of organic acids, hydrogen peroxide and mild heat on inactivation of Escherichia coli O157: H7 on baby spinach. Food Control, vol. 22, n. 8, p. 1178-1183. http://dx.doi.org/10.1016/j. foodcont.2011.01.012

Huang, Y.; Ye, M. \& Chen, H. (2012) - Efficacy of washing with hydrogen peroxide followed by aerosolized antimicrobials as a novel sanitizing process to inactivate Escherichia coli O157: H7 on baby spinach. International Journal of Food Microbiology, vol. 153, n .3, p. 306-313. http://dx.doi.org/10.1016/.ijfoodmicro.2011.11.018 
Joshi, K., Mahendran, R.; Alagusundaram, K.; Norton, T. \& Tiwari, B.K. (2013) - Novel disinfectants for fresh produce. Trends in Food Science \& Technology, vol. 34, n. 1, p. 54-61. http://dx.doi.org/10.1016/j.tifs.2013.08.008

Kim, J.G.; Yousef, A. \& Dave, S. (1999) - Application of ozone for enhancing the microbiological safety and quality of food: a review. Journal of Food Protection, vol. 62, n. 9, p. 1071-1087.

Kim, H. \& Song, K.B. (2017) - Combined treatment with chlorine dioxide gas, fumaric acid, and ultraviolet-C light for inactivating Escherichia coli 0157:H7 and Listeria monocytogenes inoculated on plums. Food Control, vol. 71, p. 371-375. http://dx.doi.org/10.1016/j.foodcont.2016.07.022

Kitis, M. (2004) - Disenfection of wasterwater with peracetic acid: a review. Environment International, vol. 30, n. 1, p. 47-55. http://dx.doi.org/10.1016/S0160-4120(03)00147-8

López-Gálvez, F.; Allende, A.; Selma, M.V. \& Gil, M.I. (2009) - Prevention of Escherichia coli cross-contamination by different commercial sanitizers during washing of fresh-cut lettuce. International Journal of Food Microbiology, vol. 133, n. 1-2, p. 167-171. http://dx.doi.org/10.1016/j.ijfoodmicro.2009.05.017

Mahmound, B.S. \& Linton, R.H. (2008) - Inactivation kinetics of inoculated Escherichia coli O157:H7 and Salmonella enterica on lettuce by chlorine dioxide gas. Food Microbiology, vol. 25, n. 2, p. 244-252. http:// dx.doi.org/10.1016/j.fm.2007.10.015

Mahmound, B.S.M.; Bhagat, A.R. \& Linton, R.H. (2007) - Inactivation kinetics of inoculated Escherichia coli O157:H7, Listeria monocytogenes and Salmonella enterica on strawberries by chlorine dioxide gas. Food Microbiology, vol. 24, n. 7-8, p. 736-744. http://dx.doi.org/10.1016/j.fm.2007.03.006

Morais, M.L.; Alvinhão, J.E.O.; Franco, D.V.; Silva, E. B. \& Pinto, N.A.V.D. (2015) -Application of ozone aiming to keep the quality of strawberries using a low cost reactor. Revista Brasileira de Fruticultura, vol. 37, n. 3, p. 559-567. http://dx.doi.org/10.1590/0100-2945-181/14

Olaimat, A. N. \& Holley, R. A. (2012) - Factors influencing the microbial safety of fresh produce: a review. Food Microbiology, vol. 32, n. 1, p. 1-19. http://dx.doi.org/10.1016/j.fm.2012.04.016

Ölmez, H. \& Kretzschmar, U. (2009) - Potential alternative disinfection methods for organic fresh-cut industry for minimizing water consumption and environmental impact. Food Science and Technology, vol. 42, n. 3, p. 686-693. http://dx.doi.org/10.1016/j.lwt.2008.08.001

Ongeng, D.; Devlieghere, F.; Debevere, J.; Coosemans, J. \& Ryckeboer, J. (2006) - The efficacy of electrolysed oxidising water for inactivating spoilage microrganisms in process water and on minimally processed vegetables. International Journal of Food Microbiology, vol. 109, n. 3, p. 187-197. http://dx.doi.org/10.1016/j. ijfoodmicro.2005.12.013

Park, E.J.; Alexander, E.; Taylor, G.A.; Costa, R. \& Kang, D.H. (2009) - The decontaminative effects of acidic electrolyzed water for Escherichia coli O157:H7, Salmonella Typhimurium, and Listeria monocytogenes on green onions and tomatoes with differing organic demands. Food Microbiology, vol. 26, n. 4, p. 386-390. http://dx.doi.org/10.1016/j.fm.2008

Parish, M.E.; Beuchat, L.R.; Suslow, T.V.; Harris, L.J.; Garret, E.H.; Farber, J.N. \& Busta, F.F. (2003) - Methods to reduce/eliminate pathogens form fresh and fresh-cut produce. Comprehensive Reviews in Food Science and Food Safety, vol. 2, sup. 1, p. 161-173. http://dx.doi.org/10.1111/j.1541-4337.2003.tb00033.x

Piyasena, P.; Mohareb, E.; Mckellar, R.C. (2003) - Inactivation of microbes using ultrasound: a review. International Journal of Food Microbiology, vol. 87, n. 3, p. 207-216. http://dx.doi.org/10.1016/S0168-1605(03)00075-8

Rico, D.; Martín-Diana, A.B.; Barat, J.M. \& Barry-Ryan, C. (2007) - Extending and measuring the quality of fresh-cut fruit and vegetables: a review. Trends in Food Science and Technology, vol. 18, n. 7, p. 373-386.

Rosário, D.K.A.; Mutz, Y.S.; Peixoto, J.M.C.; Oliveira, S.B.S.; Carvalho, R.V.; Carneiro, J.C.S.; São José, J.F.B. \& Bernardes, P.C. (2017) - Ultrasound improves chemical reduction of natural contaminant microbiota and Salmonella enterica subsp. enterica on strawberries. International Journal of Food Microbiology, vol. 241, p. 23-29. http://dx.doi.org/10.1016/j.ijfoodmicro.2016.10.009

Ruíz-Cruz, S.; Félix, E.A.; Cinco, M.D.; Osuna, M.A.I. \& Aguilar, G.A.G. (2007) - Efficacy of sanitizers in reducing Escherichia coli O157:H7, Salmonella spp. and Listeria monocytogenes populations on fresh-cut carrots. Food Control, vol. 18, n. 11, p. 1383-1390. http://dx.doi.org/10.1016/j.foodcont.2006.09.008

Sagong, H.G.; Lee, S.Y.; Chang, P.S.; Heu, S.; Ryu, S.; Choi, Y.J. \& Kang, D.H. (2011) - Combined effect of ultrasound and organic acids to reduce Escherichia coli O157: H7, Salmonella Typhimurium, and Listeria monocytogenes on organic fresh lettuce. International Journal of Food Microbiology, vol. 145, n. 1, p. 287-292. http://dx.doi.org/10.1016/j.ijfoodmicro.2011.01.010 
Sango, D. M.; Abela, D.; McElhatton, A. e Valdramidis, V.P. (2014) - Assisted ultrasound applications for the production of safe foods. Journal of Applied Microbiology, vol. 116, n. 5, p. 1067-1083. http://dx.doi.org/10.1111/ jam.12468

São José, J.F.B.; Andrade, N.J.; Ramos, A.M.; Vanetti, M.C.D.; Stringheta, P.C. e Chaves, J.B.P. (2014a) Decontamination by ultrasound application in fresh fruits and vegetables. Food Control, vol. 45, p. 36-50. http://dx.doi.org/10.1016/j.foodcont.2014.04.015

São José, J.F.B.; Medeiros, H.S.; Bernardes, P.C. e Andrade, N.J. (2014b) - Removal of Salmonella enterica Enteritidis and Escherichia coli from green peppers and melons by ultrasound and organic acids. International Journal of Food Microbiology, vol. 190, p. 9-13. http://dx.doi.org/10.1016/j.ijfoodmicro.2014.08.015

São José, J.F.B. e Vanetti, M.C.D. (2012) - Effect of ultrasound and commercial sanitizers on natural microbiota and Salmonella enterica Typhimurium on cherry tomatoes. Food Control, vol. 24, n. 1-2, p. 95-99. http:// dx.doi.org/10.1016/j.foodcont.2011.09.008

São José, J.F.B. e Vanetti, M.C.D. (2015) - Application of ultrasound and chemical sanitizers to watercress, parsley and strawberry: Microbiological and physicochemical quality. LWT - Food Science and Technology, vol. 63, n. 2, p. 946-952. http://dx.doi.org/10.1016/j.lwt.2015.04.029

Selma, M.V.; Ibañez, A.M.; Allende, A.; Cantwella, M. e Suslow, T. (2008) - Effect of gaseous ozone and hot water on microbial and sensory quality of cantaloupe and potential transference of Escherichia coli O157:H7 during cutting. Food Microbiology, vol. 25, n. 1, p. 162-168. http://dx.doi.org/10.1016/j.fm.2007.06.003

Seymour, I.J.; Burfoot, D.; Smith, R.L.; Cox, L.A. e Lockwood, A. (2002) - Ultrasound decontamination of minimally processed fruits and vegetables. International Journal of Food Science and Technology, vol. 37, n. 5, p. 547-557. http://dx.doi.org/10.1046/j.1365-2621.2002.00613.x

Silva, J.P.; Costa, S.M.; Oliveira, L.M.; Vieira, M.C.S.; Vianello, F. e Lima, G.P.P. (2015) - Does the use of ozonized water influence the chemical characteristics of organic cabbage (Brassica oleracea var. capitata)? Journal of Food Science and Technology, vol. 52, n. 11, p. 7026-7036. http://dx.doi.org/10.1007/s13197-015-1817-0

Silva, S.B.; Luvielmo, M.M.; Geyer, M.C. e Prá, I. (2011) - Potencialidades do uso do ozônio no processamento de alimentos. Semina: Ciências Agrárias, vol. 32, n. 2, p. 659-682.

Srebernich, S.M. (2007) - Utilização do dióxido de cloro e do ácido peracético como substitutos ao hipoclorito de sódio na sanitização do cheiro-verde minimamente processado. Ciência e Tecnologia de Alimentos, vol. 27. n. 4, p.744-750. http://dx.doi.org/10.1590/S0101-20612007000400012

Srey S.; Jahid, I.K. e Ha, S.D. (2013) - Biofilm formation in food industries: a food safety concern. Food Control, vol. 31, n. 2, p. 572-585. http://dx.doi.org/10.1016/j.foodcont.2012.12.001

Ukuku, D.O. (2004) - Effect of hydrogen peroxide treatment on microbial quality and appearance of whole and fresh-cut melons contaminated with Salmonella spp. International Journal Food Microbiology, vol. 95, n. 2, p. 137-146. http://dx.doi.org/10.1016/j.ijfoodmicro.2004.01.021

Warriner, K.; Huber, A.; Fan, W. e Dunfield, K. (2009) - Recent advances in the microbial safety of fresh fruits and vegetables. Advances in Food and Nutrition Research, vol. 57, p. 155-208. http://dx.doi.org/10.1016/ S1043-4526(09)57004-0

Zambre, S.S.; Venkatesh, K.V. e Shah, N.G. (2010) - Tomato redness for assessing ozone treatment to extend the shelf life. Journal of Food Engineering, vol. 96, n. 3, p. 463-468. http://dx.doi.org/10.1016/j.jfoodeng.2009.08.027

Zhou, B.; Feng H. e Luo, Y. (2009) - Ultrasound enhanced sanitizer efficacy in reduction of Escherichia coli O157:H7 population on spinach leaves. Journal of Food Science, vol. 74, n. 1, p. 308-313. http://dx.doi. org/10.1111/j.1750-3841.2009.01247.x 